\title{
Update of Intravitreal Steroids for the Treatment of Diabetic Macular Edema
}

\author{
Francesco Bandello Chiara Preziosa Giuseppe Querques Rosangela Lattanzio \\ Department of Ophthalmology, University Vita-Salute, Scientific Institute San Raffaele, Milan, Italy
}

\author{
Key Words \\ Diabetic macular edema - Intravitreal pharmacotherapies · \\ Steroids · Triamcinolone acetonide · Fluocinolone \\ acetonide - Dexamethasone implant
}

\begin{abstract}
Diabetic macular edema is considered the most important factor related to visual impairment in patients with diabetic retinopathy. Together with the use of grid and focal laser photocoagulation, today the intravitreal administration of pharmacotherapies represents the standard of care for the treatment of this complication: anti-vascular endothelium growth factor agents and steroids are the drugs currently used for this aim. Differently from laser therapy, which prevents visual deterioration, the intravitreal approach allows the promotion of visual recovery. However, the intravitreal injections require to be repeated with high frequency, and this carries the risk of drug- and procedure-related adverse effects.

(c) 2014 S. Karger AG, Basel
\end{abstract}

\section{Introduction}

Diabetic macular edema (DME) is the leading cause of visual impairment in people with diabetes mellitus [1]. The prevalence of diabetes is growing quickly in the population [2], so that the development of DME in workingage people will represent an increasing problem to deal with in the near future [3]. DME is a sight-threatening complication which needs a timely treatment; more than $50 \%$ of incorrectly treated patients lose several lines of visual acuity (VA) within a few years [4].

For many years now grid and focal laser photocoagulation have been considered the standard therapy for the treatment of visual impairment due to DME [5]; however, laser therapy acts upon vision stabilization with the destruction of retinal tissue and does not control all cases of DME. In the Early Treatment Diabetic Retinopathy Study (ETDRS), patients with vision loss due to DME who were immediately treated with laser therapy had a reduction by half of the risk of losing 15 letters of VA compared to those receiving a deferred treatment [6]. More recent studies reported a VA improvement of only 0.9 letters [7] and 3 letters [8] for patients treated with laser monotherapy according to ETDRS criteria; however, in the Diabetic Retinopathy Clinical Research Network trial(DRCR. net) [9] a small group of laser-treated patients (21\%) achieved a gain of 15 letters in VA at 2 years, suggesting a delayed benefit related to laser therapy. Therefore, even if trying to prevent further vision loss is important, today therapies that could restore VA in patients with visual impairment related to DME are certainly required.

With the development of intravitreal pharmacotherapies such as antivascular endothelium growth factor (anti-VEGF) agents and steroids, new strategies in the management of this complex disease have been recommended. Compared to laser procedure, the intravitreal approach has the great advantage of potentially promoting visual

\section{KARGER}

E-Mail karger@karger.com

www.karger.com/ore
C 2014 S. Karger AG, Basel

0030-3747/14/0522-0089\$39.50/0
Francesco Bandello, MD, FEBO

Department of Ophthalmology, University Vita-Salute Scientific Institute San Raffaele

Via Olgettina 60, IT-20132 Milan (Italy)

E-Mail bandello.francesco@ hsr.it 
Table 1. Intravitreal steroids under investigation for the treatment of DME

\begin{tabular}{lllll}
\hline Drug & Dosage & Biological features & Surgical procedure & Duration of action \\
\hline Triamcinolone acetonide & $1 \mathrm{or} 4 \mathrm{mg}$ & Biodegradable & Intravitreal injection & $2-4$ months (depending on the dosage) \\
Fluocinolone acetonide (Retisert) & $0.59 \mathrm{mg}$ & Nonbiodegradable & Surgical incision and suture & 3 years \\
Fluocinolone acetonide (Iluvien) & $250 \mu \mathrm{g}(0.2$ or & Nonbiodegradable & Prefilled, single-use, 25-gauge needle & 3 years \\
& $0.5 \mu \mathrm{g} /$ day $)$ & Biodegradable & Prefilled, single-use, 22-gauge applicator & $4-6$ months \\
DEX implant (Ozurdex) & $0.7 \mathrm{mg}$ & B & & \\
\hline
\end{tabular}

Modified from Bandello et al. [56].

recovery; however, this new strategy usually requires repeated interventions, with a higher risk of drug- or procedure-related adverse effects.

VEGF is a homodimeric protein which acts by stimulating the proliferation of vascular endothelial cells and inducing an increase in vascular permeability [10]. Several studies have highlighted a central role of this factor in promoting DME development $[11,12]$; from these studies came the idea to highlight therapeutic agents in order to contrast the VEGF functions. The main anti-VEGF agents studied for the treatment of DME are ranibizumab (Lucentis $\left.{ }^{\circledR}\right)$, bevacizumab $\left(\right.$ Avastin $\left.^{\circledR}\right)$ and pegaptanib sodium (Macugen ${ }^{\circledR}$ ); in addition, recent results have also reported an interesting role of aflibercept (VEGF Trap-Eye, Eylea). The efficacy and safety of these drugs have been carefully compared to placebo and to laser photocoagulation, showing favorable results [13-23]. In particular, ranibizumab (Lucentis; Novartis Pharma AG, Basel, Switzerland and Genentech Inc., San Francisco, Calif., USA) was recently approved by the European Medicines Agency for the treatment of visual impairment due to DME [24].

The use of steroids for the treatment of DME has been studied for many years because of their strong anti-inflammatory and anti-edema properties. Several studies clearly reported the effect of steroids in reducing VEGF expression, leukostasis and inflammatory cytokine production $[25,26]$. Different classes of intravitreal steroids are available today; they differ in biological properties and duration of action (table 1). Steroids administered intravitreally stabilize VA and reduce DME, but they are also associated with frequent side effects, the most frequent (reported from all types of steroids) being an increase in intraocular pressure (IOP) and cataract progression. For this reason they are generally used in patients affected by persistent or refractory DME, especially in pseudophakic eyes.

In this review we focus on the more relevant evidence for the use of steroids in patients with DME, reporting their efficacy for the treatment of this complex disease. Three different types of intravitreal steroid are now available: triamcinolone acetonide, fluocinolone acetonide and dexamethasone. Fluocinolone acetonide and dexamethasone are contained in sustained-release drug delivery devices that, inserted into the vitreous, allow the release of the steroid with a longer duration of action, reducing the number of intravitreal injections.

\section{Clinical Trial Evidence for Intravitreal Triamcinolone Acetonide in DME}

Intravitreal triamcinolone acetonide (IVTA) is commercially available today in suspension form with the names, among others, Trivaris (Allergan, Irvine, Calif., USA), Kenacort (Bristol-Myers-Squibb, Melbourne, Vic., Australia) and Kenalog (Bristol-Myers-Squibb, Princeton, N.Y., USA). IVTA was first reported for the treatment of age-related macular degeneration [27]; some years later, it was also used for the treatment of DME [28].

Since 1991 IVTA has been used in many small case series and randomized clinical trials (RCTs) [29-33]; different IVTA injection strategies, administered with a single injection (4 or $20 \mathrm{mg}$ ) [29-32] or with multiple injections (4 mg) for up to 2 years [33], have been compared with observation. These studies were later evaluated in a Cochrane review, the data of which showed some favorable results, although IVTA was unfortunately associated with an increased risk of side effects. In particular, the results showed a 1-line improvement of VA at 3 months in an eye receiving a single IVTA injection, but this was not maintained at 6 months [32]. However, in the group receiving multiple injections, an IVTA treatment effect was still present at the 2-year follow-up [33]. It has been assumed that with the strategy of a single injection there is a gradual reduction in the drug concentration in the eye, leading to a drop-off effect, while the possibility to receive 
a reinjection of IVTA, in the case of a decline in VA, promotes a more sustained effect.

An earlier RCT evaluated the effect of IVTA $(4 \mathrm{mg})$ for the treatment of refractory DME [34]. In a 2-year followup period, IVTA showed a best-corrected VA (BCVA) improvement in $56 \%$ of the treated eyes (with a mean number of 2.6 injections) compared to $26 \%$ of the control group; it also revealed an increased risk of cataract progression (54\% of treated patients vs. $0 \%$ of controls) and a rise in IOP, requiring topical medication ( $44 \mathrm{vs.} 3 \%$, respectively). Moreover, the effects of IVTA in refractory DME have been investigated for 5 years [35]. All eyes, including those initially randomized to the placebo group, were switched to receive IVTA. The results showed a gain of 5 or more letters in $42 \%$ of the treated eyes compared to $32 \%$ of eyes initially treated with placebo and then with IVTA. Therefore, the majority of eyes that initially improved with IVTA maintained their gain after 5 years and some of the eyes initially not treated had a visual improvement, suggesting the usefulness of IVTA in carefully selected cases with impaired vision caused by advanced DME that do not respond to other interventions.

The efficacy of IVTA for the treatment of DME was compared to macular laser photocoagulation. Although an early RCT showed better results in terms of VA gain in patients treated with IVTA [36], the 3-year results of theDRCR.net [38] did not demonstrate a long-term advantage of IVTA compared to macular laser photocoagulation. The DRCR.net compared the efficacy and safety of preservative-free IVTA to focal/grid laser photocoagulation (considered the standard of care) for the treatment of DME in a follow-up period of 2 years, which was then extended to 3 years $[37,38]$. Patients were randomized to $3 \mathrm{arms}$ to receive focal/grid laser photocoagulation, IVTA $1 \mathrm{mg}$ or IVTA $4 \mathrm{mg}$, respectively. Even if a greater gain in BCVA was reported in the IVTA 4-mg arm at 4 months, nonsignificant differences in BCVA were noticed among the 3 groups after the first year. However, at the 2 -year end point, mean BCVA was better in the laser group, and this result was also confirmed by the central retinal thickness (CRT) measurements from optical coherence tomography. These data were confirmed in the expanded 3-year follow-up: the laser group presented a BCVA improvement of +5 letters while no BCVA change was noticed in the 2 IVTA groups (+0 letters). With regard to the side effects, at the third year an IOP increase of $\geq 10 \mathrm{~mm} \mathrm{Hg}$ was reported in 4,18 and $33 \%$ of the 3 arms, respectively, with an increased probability of cataract surgery in 31, 46 and $83 \%$. Therefore, the authors concluded that the IVTA approach did not reveal long-term benefits in the treat-

Intravitreal Steroids for Treatment of DME: Update ment of DME compared to laser photocoagulation. An additional analysis was performed on the participants of this study in order to evaluate the effects of IVTA injection compared to laser therapy on the progression of diabetic retinopathy (DR) at 3 years [39]. Data showed a reduction in the risk of DR progression in patients treated with IVTA $4 \mathrm{mg}$ compared to the IVTA $1 \mathrm{mg}$ and laser groups ( 21 vs. 29 vs. $31 \%$, respectively). Nevertheless, the use of IVTA as a therapeutic strategy to reduce or slow down the progression of DR was not suggested by the authors.

Later, the DRCR.net performed a large RCT in order to evaluate the effects of two different intravitreal agents, triamcinolone acetonide (steroid) and ranibizumab (antiVEGF agent) for the treatment of center-involving DME. In the trial the effectiveness of different combined strategies, including an intravitreal drug associated with grid/ focal laser photocoagulation, were compared to laser monotherapy during a follow-up of 1 year, which was then extended to 2 years $[8,9]$. The enrolled patients were randomly assigned to 4 arms: sham injection plus laser, $0.5 \mathrm{mg}$ of intravitreal ranibizumab (IVR) plus prompt laser, $0.5 \mathrm{mg}$ IVR plus deferred laser and $4 \mathrm{mg}$ IVTA plus prompt laser. At the first year end point [8] data showed a greater benefit in terms of BCVA gain in the groups with IVR plus prompt or deferred laser compared to the arms with IVTA plus laser and laser alone; the 3 study groups evaluating IVTA or IVR plus laser also revealed similar results in CRT measurements, with a greater reduction in CRT compared to the group with laser alone. At the extended 2-year follow-up the results were consistent with those published after the first year [9]. Compared to the group with laser alone, the mean change in BCVA was +3.7 letters better in the group with IVR plus prompt laser, +5.8 letters greater in the group with IVR plus deferred laser and -1.5 letters worse in the group with IVTA plus prompt laser. The steroidal approach affirmed a good security profile despite a greater incidence of cataract, which in phakic patients limited the visual gain and required surgery in $55 \%$ of cases versus $12 \%$ in the IVR group. In contrast, in the subgroup of pseudophakic eyes, the IVTA plus laser strategy provided greater benefits than laser alone, and it was not inferior to the IVR plus laser option. However, an increased risk of IOP rise was noticed in all groups treated with the steroid (38\% in IVTA plus laser vs. 5\% in IVR plus laser). Therefore, the authors indicated the IVR injection as an efficient treatment for DME with macular involvement; on the other hand, the IVTA strategy could probably represent an alternative option in pseudophakic patients.

Another RCT promoted by the DRCR.net evaluated the effects of ranibizumab and triamcinolone acetonide 
Table 2. Main clinical trials that evaluated the use of steroids for the treatment of DME

\begin{tabular}{|c|c|c|c|c|c|}
\hline Study & Name of steroid & $\begin{array}{l}\text { Number } \\
\text { of eyes }\end{array}$ & Study design & Follow-up & Major conclusions \\
\hline $\begin{array}{l}\text { Gillies } \\
{[35], 2009}\end{array}$ & $\begin{array}{l}\text { Triamcinolone } \\
\text { acetonide }\end{array}$ & $69 \rightarrow 44$ & $\begin{array}{l}\text { IVTA ( } 4 \mathrm{mg} \text { ) vs. sham; } \\
\text { laser if appropriate }\end{array}$ & 5 years & $\begin{array}{l}\text { Final VA comparable; delayed intervention } \\
\text { did not compromise the possibility to } \\
\text { respond (advanced DME) }\end{array}$ \\
\hline $\begin{array}{l}\text { DRCR.net } \\
{[37], 2009}\end{array}$ & $\begin{array}{l}\text { Triamcinolone } \\
\text { acetonide }\end{array}$ & $840 \rightarrow 306$ & $\begin{array}{l}\text { IVTA ( } 1 \text { or } 4 \mathrm{mg}) \text { vs. } \\
\text { laser }\end{array}$ & 3 years & $\begin{array}{l}\text { Laser: }+5 \text { letters; IVTA arms: } 0 \text { letters; no real } \\
\text { long-term advantage of IVTA despite laser }\end{array}$ \\
\hline $\begin{array}{l}\text { DRCR.net } \\
{[39], 2011}\end{array}$ & $\begin{array}{l}\text { Triamcinolone } \\
\text { acetonide }\end{array}$ & 854 & $\begin{array}{l}\text { IVR }(0.5 \mathrm{mg})+\text { prompt } \\
\text { or deferred laser vs. } \\
\text { IVTA }(4 \mathrm{mg})+\text { prompt } \\
\text { laser vs. laser }\end{array}$ & 2 years & $\begin{array}{l}\text { Compared to laser, IVR + laser groups } \\
\text { improved VA; IVTA group did not; in } \\
\text { pseudophakic eyes IVTA made a VA } \\
\text { improvement equal to IVR }\end{array}$ \\
\hline $\begin{array}{l}\text { Pearson } \\
{[41], 2011}\end{array}$ & $\begin{array}{l}\text { Fluocinolone } \\
\text { acetonide (Retisert) }\end{array}$ & 196 & $\begin{array}{l}\text { Retisert insert }(0.59 \mathrm{mg}) \\
\text { vs. laser or observation }\end{array}$ & 3 years & $\begin{array}{l}\text { Better VA and CRT improvement of IVFA } \\
\text { group at } 2 \text { years, but not at } 3 \text { years; high } \\
\text { incidence of cataract and glaucoma }\end{array}$ \\
\hline $\begin{array}{l}\text { Haller } \\
{[49], 2010}\end{array}$ & $\begin{array}{l}\text { Dexamethasone } \\
\text { (Ozurdex) }\end{array}$ & 171 & $\begin{array}{l}\text { DEX implant ( } 700 \text { or } \\
350 \mu \mathrm{g}) \text { vs. sham }\end{array}$ & 6 months & $\begin{array}{l}\text { VA improvement } \geq 10 \text { letters in more treated } \\
\text { eyes, especially the } 700 \text { - } \mu \text { g group; IOP } \\
\text { increase effectively treated with topical } \\
\text { medication }\end{array}$ \\
\hline
\end{tabular}

Modified from Stewart [57].

in eyes previously treated with focal/grid laser for DME and panretinal photocoagulation for DR [40]. In this study, the addition of 1 IVTA or 2 IVR injections in eyes formerly treated with laser of the periphery and posterior pole was associated with VA improvement and decreased macular edema at 14 weeks, but not at 56 weeks.

Today, indications for the use of IVTA for DME have not been established. Triamcinolone is available in Europe for some other therapeutic indications (intra-articular use) and so the intravitreal administration must be considered off-label. Nevertheless, the role of IVTA alone or as an adjunct to laser could be carefully considered in selected cases of visual loss due to persistent or refractory DME, especially in pseudophakic eyes (table 2).

\section{Clinical Trial Evidence for Intravitreal Fluocinolone Acetonide in DME}

Fluocinolone acetonide is an attractive drug because of its potency, solubility and lipophilicity. It has been formulated into two different types of sustained drug deliv- ery devices: Retisert ${ }^{\circledR}$ (Bausch \& Lomb, Rochester, N.Y., USA) and Iluvien ${ }^{\circledR}$ (Alimera Sciences, Atlanta, Ga., USA). These innovative sustained-release implants have already been tested and might have some potential in the treatment of persistent DME.

Retisert is a nonbiodegradable device containing 0.59 $\mathrm{mg}$ of fluocinolone acetonide, which is inserted into the vitreous through a pars plana incision and is well developed to release sustained levels of the drug for almost 30 months. After the surgical implantation of the device, the steroid is released into the eye at an initial rate of about $0.6 \mu \mathrm{g} /$ day and then progressively decreased to a steady rate of nearly $0.3-0.4 \mu \mathrm{g} / \mathrm{day}$ after the first month. Retisert has been approved as a validated treatment option of chronic, noninfectious posterior uveitis [41] but not for DME as yet. However, a large multicenter RCT has recently tested the efficacy and safety of Retisert for the treatment of persistent or recurrent DME; the study design considered a 4-year follow-up, and data at 3 years have already been published [42]. In detail, patients were randomized to 2 arms: Retisert implant $(0.59 \mathrm{mg})$ or observation/additional laser photoco- 
agulation (considered the standard of care). Data revealed a BCVA gain of 3 or more lines in $16.8 \%$ of implanted eyes after 6 months, $16.4 \%$ after 1 year, $31.8 \%$ after 2 years, and $31.1 \%$ after 3 years compared to 1.4 , $8.1,9.35$ and $20 \%$ in the standard of care group at the same time points. Compared to the standard of care group, a higher rate of reduction of CRT at each time point was also noticed in the treated group. Nevertheless, the results also showed a higher frequency of secondary effects related to intravitreal fluocinolone acetonide (IVFA) treatment: at the end of the 4-year followup cataract extraction was needed in $91 \%$ of phakic eyes, and $33.8 \%$ of treated eyes required surgical management of IOP elevation $(\geq 30 \mathrm{~mm} \mathrm{Hg}$, which was observed in $61.4 \%$ of all treated eyes at any follow-up time). Despite the high incidence of complications, the authors suggested the IVFA implant as a possible approach in patients with recurrent or persistent DME.

Iluvien is a smaller, long-lasting nonbiodegradable insert containing $250 \mu \mathrm{g}$ of fluocinolone acetonide. It is injected into the vitreous through a 25-gauge needle and engineered to release 0.5 or $0.2 \mu \mathrm{g} /$ day of the active principle [43]. The efficacy of Iluvien insert for the treatment of DME resistant to laser was evaluated in recent RCTs, with a 3-year follow-up period (FAME studies) [44, 45]. Patients with persistent DME and at least one prior laser treatment were randomly assigned to 3 arms: IVFA $0.2 \mu \mathrm{g} /$ day (low dose), IVFA $0.5 \mu \mathrm{g} /$ day (high dose) or sham injection. Data showed a BCVA improvement of 15 or more letters in $28.7,27.8$ and $18.9 \%$ of the 3 groups, respectively, at both 24 and 36 months. Retreatment was possible after 12 months and it was performed in $25 \%$ of patients (with a mean number of 4 inserts over 3 years). Moreover, about $40 \%$ of patients underwent rescue laser treatment. In addition, to evaluate whether the duration of DME could play a role in determining the response to therapy, a further analysis has been developed which clearly revealed that the response to IVFA was better in the subgroup of patients with long-lasting DME. In particular, for patients with a mean disease duration of 3 or more years, the number of significant responses (BCVA gain of 15 or more letters) was significantly higher in the group treated with the steroid implant. In contrast, the number of patients with a mean duration of DME of less than 3 years who presented an adequate BCVA improvement (15 or more letters) was not significant [45]. Unfortunately, side effects were frequent; almost all phakic eyes required cataract extraction and the rate of glaucoma needing surgical intervention was 4.8 and $8.1 \%$ in the low- and high-dose groups, respectively. Despite the high frequency of cataract and glaucoma, the authors concluded that the IVFA implant could be a valuable therapeutic option in eyes with chronic DME that were refractory to previous treatments, owing to the high rate of response.

Because of its adverse events, IVFA has failed to receive the Food and Drug Administration (FDA) approval in the USA. Nevertheless, Iluvien is approved in several European countries for the treatment of refractory/ persistent DME (table 2).

\section{Clinical Trial Evidence for Dexamethasone Intravitreal Implant in DME}

Dexamethasone intravitreal implant (DEX implant, Ozurdex ${ }^{\circledR}$; Allergan) is a biodegradable device containing $0.7 \mathrm{mg}$ of preservative-free dexamethasone. The device is injected into the vitreous through a prefilled, single-use, 22-gauge applicator, and it was engineered to deliver the drug with slow-release kinetics. DEX was first used together with antibiotics for the medical treatment of bacterial endophthalmitis; today the DEX sustaineddelivery system has been approved and validated by the FDA in the USA and by the European Union (EU) for the treatment of patients with chronic noninfectious posterior uveitis [46] and macular edema due to retinal vein occlusion [47].

The efficacy and safety of the DEX implant has been evaluated in patients with DME [48-55]. First, in a 6-month RCT, patients with persistent macula edema secondary to different pathologies, including DME, retinal vein occlusion, Irvine-Gass syndrome and uveitis, received the DEX implant (700 or $350 \mu \mathrm{g}$ ) or a sham injection [49]. At the 3-month follow-up data showed a BCVA gain of 10 or more letters in 35\% (700 $\mu \mathrm{g})$ and $24 \%$ $(350 \mu \mathrm{g})$ of the DEX implant arms, respectively, compared to $13 \%$ of the sham group. An IOP increase of $10 \mathrm{~mm} \mathrm{Hg}$ or higher was detected in $11 \%$ of both of the DEX implant groups compared to $2 \%$ of the control group.

A further analysis of this study evaluated the effects of dexamethasone in the specific subgroup of patients affected by DME, revealing a potential role of the DEX implant for the treatment of persistent DME [50]. In particular, at the third month a BCVA improvement of 10 or more letters was observed in 33.3, 21.1 and $12.3 \%$ of the 3 groups (DEX $700 \mu \mathrm{g}$, DEX $350 \mu \mathrm{g}$ and sham group), respectively. Furthermore, the visual gain was maintained until the 6-month follow-up in 30,19 and $23 \%$ of the 3 
groups, respectively. A great improvement in CRT and fluorescein leakage was also noticed in the treated eyes. Regarding the side effects, an IOP increase reaching values $\geq 25 \mathrm{~mm} \mathrm{Hg}$ was detected in 12.7, 7.5 and $0 \%$ of the 3 groups, respectively, but it was effectively treated with topical medications.

The efficacy of the DEX implant has also been evaluated in eyes affected by DME refractory to pars plana vitrectomy, revealing a significant improvement in BCVA measurements, CRT values and vascular leakage after 26 weeks [51]. In this study the DEX implant was injected into vitrectomized eyes, revealing a mean gain in BCVA of 6 and 3 letters and a mean reduction in CRT of 156 and $39 \mu \mathrm{m}$ at weeks 8 and 26 , respectively, showing a sustained treatment effect despite previous surgery.

A further 2 RCTs assessed the efficacy and safety of the DEX implant in small study populations affected by persistent DME [52, 53]. These studies reported similar results, showing an effect of the DEX implant in producing an improvement in BCVA and CRT measurements from the first and third day after injection until the fourth and third month, respectively. Moreover, a recent trial investigated the use of the DEX implant in patients with chronic DME nonresponsive to intravitreal anti-VEGF treatment (3 consecutive monthly injections) [54]. As with previous results, this study also revealed the efficacy of the DEX implant, with an improvement of BCVA and CRT values until 4 months. A slight increase in IOP was noticed in all recruited patients, which did not require surgical intervention.

However, a recent trial compared a DEX implant plus laser combination therapy to laser alone for the treatment of diffuse DME [55]. Although a greater improvement of BCVA with a gain of 10 or more letters was seen from the first to the ninth month in the combination group, this difference was not confirmed at 12 months.

Recently, a phase III, multicenter, masked, randomized, sham-controlled trial evaluated the safety and efficacy of 700 and $350 \mu \mathrm{g}$ of the dexamethasone posterior segment drug delivery system (DEX PS DDS ${ }^{\circledR}$ ) applicator system in the treatment of DME. More than 1,000 patients were randomized to each of the 3 arms of the study: DEX $700 \mu \mathrm{g}$, DEX $350 \mu \mathrm{g}$ or sham delivered by sustained-release implant. Retreatments were delivered every 6 months, if necessary. According to the results, the percentage of patients with a gain of 15 or more letters was significantly greater in the DEX-treated patients than in the sham-treated group at 3 years, which was the primary end point. Furthermore, treatment benefit was observed with a mean of 4.1 injections over the 36 months of follow-up. The safety profile was as good as or better than that in other studies; IOP elevations rarely required treatment and there was no evidence of increased systemic adverse events or risk of arterial thromboembolic events after repeated treatment [Boyer D.S., MEAD Study - data presented at AAO meeting, New Orleans, 2013].

The DEX implant has not yet received FDA and EU approval for its use in DME. Nevertheless, it should be considered as an effective therapeutic option in patients with recurrent or persistent DME, especially in pseudophakic eyes (table 2).

\section{Conclusions}

Nowadays, the combination of intravitreal antiVEGF agents and macular laser photocoagulation is considered the standard of care for the treatment of patients with DME. However, intravitreal steroid injections or implants showed favorable results as a therapeutic option for the management of DME, especially as an additional choice in pseudophakic patients and in patients previously treated with anti-VEGF agents, laser and vitrectomy with poor results. The major problem with steroid use is related to the high rates of intraocular complications.

Several investigations have tried to reveal the role of combination therapy as a valuable, long-lasting option in order to improve the patient's response and reduce the frequency of retreatment. For this purpose a practical therapeutic algorithm for the treatment of DME has recently been proposed [56].

To conclude, we expect to assist in a continuous increment in the use of steroids for selected patients with DME, especially as an alternative strategy for eyes in which laser and anti-VEGF agents have failed.

References

\footnotetext{
$\checkmark 1$ Aroca PR, Salvat M, Fernandez J, et al: Risk factors for diffuse and focal macular edema. J Diabetes Compl 2004;18:211-215.

12 Wild S, Roglic G, Green A, et al: Global prevalence of diabetes: estimates for the year 2000 and projections for 2030. Diabetes Care 2004; 27:1047-1053.

3 Chen E, Looman M, Laouri M, et al: Burden of illness of diabetic macular edema: literature review. Curr Med Res Opin 2010;26:15871597.

4 Ferris FL III, Patz A: Macular edema. A complication of diabetic retinopathy. Surv Ophthalmol 1984;28(suppl):452-461.
} 
5 American Academy of Ophthalmology Retina Panel Preferred Practice Pattern Guidelines: Diabetic Retinopathy. San Francisco, American Academy of Ophthalmology, 2010.

-6 Early Treatment Diabetic Retinopathy Study Research Group: Photocoagulation for diabetic macular edema. Early Treatment Diabetic Retinopathy Study report number 1 . Arch Ophthalmol 1985;103:1796-1806.

7 Mitchell P, Bandello F, Schmidt-Erfurth U, et al: The RESTORE study: ranibizumab monotherapy or combined with laser versus laser monotherapy for diabetic macular edema. Ophthalmology 2011;118:615-625.

8 Diabetic Retinopathy Clinical Research Network: Randomized trial evaluating ranibizumab plus prompt or deferred laser or triamcinolone plus prompt laser for diabetic macular edema. Ophthalmology 2010;117: 1064-1077.

-9 Diabetic Retinopathy Clinical Research Network: Expanded 2-year follow-up of ranibizumab plus prompt or deferred laser or triamcinolone plus prompt laser for diabetic macular edema. Ophthalmology 2011;118: 609-614.

10 Bhagat N, Grigorian RA, Tutela A, et al: Diabetic macular edema: pathogenesis and treatment. Surv Ophthalmol 2009;54:1-32.

-11 Funatsu H, Yamashita H, Noma H, et al: Increased levels of vascular endothelial growth factor and interleukin-6 in the aqueous humor of diabetics with macular edema. Am J Ophthalmol 2002;133:70-77.

12 Funatsu H, Yamashita H, Ikeda T, et al: Vitreous levels of interleukin- 6 and vascular endothelial growth factor are related to diabetic macular edema. Ophthalmology 2003;110: 1690-1696.

13 Nguyen QD, Tatlipinar S, Shah SM, et al: Vascular endothelial growth factor is a critical stimulus for diabetic macular edema. Am J Ophthalmol 2006;142:961-969.

14 Massin P, Bandello F, Garweg JG, et al: Safety and efficacy of ranibizumab in diabetic macular edema (RESOLVE study): a 12-month, randomized, controlled, double-masked, multicenter phase II study. Diabetes Care 2010;33:2399-2405.

15 Nguyen QD, Brown DM, Marcus DM, et al: Ranibizumab for diabetic macular edema: results from 2 phase III randomized trials: RISE and RIDE. Ophthalmology 2012;119:789801.

16 Do DV, Nguyen QD, Khwaja AA, et al: Ranibizumab for Edema of the Macula in Diabetes Study: 3-year outcomes and the need for prolonged frequent treatment (READ-2). Arch Ophthalmol 2012;8:1-7.

17 Elman MJ, Qin H, Aiello LP, et al: Intravitreal ranibizumab for diabetic macular edema with prompt versus deferred laser treatment: three-year randomized trial results. Ophthalmology 2012;119:2312-2318.

18 Scott IU, Edwards AR, Beck RW, et al: A phase II randomized clinical trial of intravit- real bevacizumab for diabetic macular edema. Ophthalmology 2007;114:1860-1867.

19 Rajendram R, Fraser-Bell S, Kaines A, et al: A 2 -year prospective randomized controlled trial of intravitreal bevacizumab or laser therapy (BOLT) in the management of diabetic macular edema: 24-month data: report 3. Arch Ophthalmol 2012;130:972-979.

20 Soheilian M, Ramezani A, Obudi A, et al: Randomized trial of intravitreal bevacizumab alone or combined with triamcinolone versus macular photocoagulation in diabetic macular edema. Ophthalmology 2009;116:11421150.

21 Cunningham ET Jr, Adamis AP, Altaweel M, et al: A phase II randomized double-masked trial of pegaptanib, an anti-vascular endothelial growth factor aptamer, for diabetic macular edema. Ophthalmology 2005;112:17471757.

22 Sultan MB, Zhou D, Loftus J, et al: A phase $2 / 3$, multicenter, randomized, doublemasked, 2-year trial of pegaptanib sodium for the treatment of diabetic macular edema. Ophthalmology 2011;118:1107-1118.

23 Do DV, Nguyen QD, Boyer D, et al: One-year outcomes of the DA VINCI Study of VEGF Trap-Eye in eyes with diabetic macular edema. Ophthalmology 2012;119:1658-1665.

24 Summary of Product Characteristics 2011. Basel, Novartis Pharma, 2011.

25 Nauck M, Roth M, Tamm M, et al: Induction of vascular endothelial growth factor by platelet-activating factor and platelet-derived growth factor is down-regulated by corticosteroids. Am J Respir Cell Mol Biol 1998;16: 398-406.

26 Tamura H, Miyamoto K, Kiryu J, et al: Intravitreal injection of corticosteroid attenuates leukostasis and vascular leakage in experimental diabetic retina. Invest Ophthalmol V is Sci 2005;46:1440-1444.

27 Penfold P, Gyory J, Hunyor A, et al: Exudative macular degeneration and intravitreal Triamcinolone. A pilot study. Aust NZ J Ophthalmol 1995;23:292-298.

28 Jonas J, Sofker A: Intraocular injection of crystalline cortisone as adjunctive treatment of diabetic macular edema. Am J Ophthalmol 2001;132:425-427.

29 Audren F, Erginay A, Haouchine B, et al: Intravitreal triamcinolone acetonide for diffuse diabetic macular oedema: 6-month results of a prospective controlled trial. Acta Ophthalmol Scand 2006;84:624-630.

30 Massin P, Audren F, Haouchine B, et al: Intravitreal triamcinolone acetonide for diabetic diffuse macular edema: preliminary results of a prospective controlled trial. Ophthalmology 2004;111:218-224.

31 Avitabile T, Longo A, Reibaldi A: Intravitreal triamcinolone compared with macular laser grid photocoagulation for the treatment of cystoid macular edema. Am J Ophthalmol 2005; 140:695-702.

32 Jonas JB, Kampperter BA, Harder B, et al: Intravitreal triamcinolone acetonide for diabet- ic macular edema: a prospective, randomized study. J Ocul Pharmacol Ther 2006;22:200207.

33 Sutter FK, Simpson JM, Gillies MC: Intravitreal triamcinolone for diabetic macular edema that persists after laser treatment: threemonth efficacy and safety results of a prospective, randomized, double-masked, placebo controlled clinical trial. Ophthalmology 2004; 111:2044-2049.

34 Gillies MC, Sutter FK, Simpson JM, et al: Intravitreal triamcinolone for refractory diabetic macular edema two-year results of a double-masked, placebo-controlled, randomized clinical trial. Ophthalmology 2006;113:15331538.

35 Gillies MC, Simpson JM, Gaston C, et al: Fiveyear results of a randomized trial with openlabel extension of triamcinolone acetonide for refractory diabetic macular edema. Ophthalmology 2009;116:2182-2187.

36 Diabetic Retinopathy Clinical Research Network: A randomized trial comparing intravitreal triamcinolone acetonide and focal/ grid photocoagulation for diabetic macular edema. Ophthalmology 2008;115:14471449.

37 Diabetic Retinopathy Clinical Research Network: Three-year follow-up of a randomized clinical trial comparing focal/grid laser photocoagulation and intravitreal triamcinolone for diabetic macular edema. Arch Ophthalmol 2009;127:245-251.

38 Bressler NM, Edwards AR, Beck RW, et al: Exploratory analysis of diabetic retinopathy progression through 3 years in a randomized clinical trial that compares intravitreal triamcinolone acetonide with focal/grid photocoagulation. Arch Ophthalmol 2009;127:15661571.

39 Diabetic Retinopathy Clinical Research Network: Randomized trial evaluating shortterm effects of intravitreal ranibizumab or triamcinolone acetonide on macular edema following focal/grid laser for diabetic macular edema in eyes also receiving panretinal photocoagulation. Retina 2011;31:1009-1027.

40 Jaffe GJ, Martin D, Callanan D, et al: Fluocinolone acetonide implant (Retisert) for non-infectious posterior uveitis: thirty-fourweek results of a multicenter randomized clinical study. Ophthalmology 2006;113: 1020-1027.

41 Pearson PA, Comstock TL, Ip M, et al: Fluocinolone acetonide intravitreal implant for diabetic macular edema: a 3-year multicenter, randomized, controlled clinical trial. Ophthalmology 2011;118:1580-1587.

42 Campochiaro PA, Hafiz G, Shah SM, et al: Sustained ocular delivery of fluocinolone acetonide by an intravitreal insert. Ophthalmology 2010;117:1393-1399.

43 Campochiaro PA, Brown DM, Pearson A, et al: Long-term benefit of sustained-delivery fluocinolone acetonide vitreous inserts for diabetic macular edema. Ophthalmology 2011; 118:626-635. 
44 Campochiaro PA, Brown DM, Pearson A, et al: Sustained delivery fluocinolone acetonide vitreous inserts provide benefit for at least 3 years in patients with diabetic macular edema. Ophthalmology 2012;119:2125-2132.

45 Lowder C, Belfort R Jr, Lightman S, et al: Dexamethasone intravitreal implant for noninfectious intermediate or posterior uveitis. Arch Ophthalmol 2011;129:545-553.

46 Haller JA, Bandello F, Belfort R Jr, et al: Randomized, sham-controlled trial of dexamethasone intravitreal implant in patients with macular edema due to retinal vein occlusion. Ophthalmology 2010;117:1134-1146.

47 Haller JA, Dugel P, Weinberg DV, et al: Evaluation of safety and performance of an applicator for a novel intravitreal dexamethasone drug delivery system for the treatment of macular edema. Retina 2009;29:46-51.
48 Kuppermann BD, Blumenkranz MS, Haller JA, et al: Randomized controlled study of an intravitreous dexamethasone drug delivery system in patients with persistent macular edema. Arch Ophthalmol 2007;125:309-317.

49 Haller JA, Kuppermann BD, Blumenkranz MS, et al: Randomized controlled trial of an intravitreous dexamethasone drug delivery system in patients with diabetic macular edema. Arch Ophthalmol 2010;128:289-296.

50 Boyer DS, Faber D, Gupta S, et al: Dexameth asone intravitreal implant for treatment of diabetic macular edema in vitrectomized patients. Retina 2011;31:915-923.

51 Zucchiatti I, Lattanzio R, Querques G, et al: Intravitreal dexamethasone implant in patients with persistent diabetic macular edema. Ophthalmologica 2012;228:117-122.

52 Pacella E, Vestri AR, Muscella R, et al: Preliminary results of an intravitreal dexamethasone implant $\left(\mathrm{Ozurdex}^{\circledR}\right)$ in patients with persistent diabetic macular edema. Clin Ophthalmol 2013;7:1423-1428.

53 Lazic R, Lukic M, Boras I, et al: Treatment of anti-vascular endothelial growth factor-resistant diabetic macular edema with dexamethasone intravitreal implant. Retina 2014;34: 719-724.
54 Callanan D, Gupta S, Boyer D, et al: Dexamethasone intravitreal implant in combination with laser photocoagulation for the treatment of diffuse diabetic macular edema. Ophthalmology 2013;120:1843-1851.

55 Bandello F, Battaglia Parodi M, Tremolada G, et al: Steroids as part of combination treatment: the future for the management of macular edema? Ophthalmologica 2010;224(suppl 1):41-45.

56 Bandello F, Zarbin MA, Lattanzio R, Zucchiatti I: Clinical Strategies in the Management of Diabetic Retinopathy: A Step-by-Step Guide for Ophthalmologists. Berlin, Springer, 2013.

57 Stewart MW: Corticosteroid use for diabetic macular edema: old fad or new trend? Curr Diab Rep 2012;12:364-375. 